\title{
Prevalence of Occupational Stress and Related Risk Factors among Nurses Working in ASEER Region
}

\author{
Maha Mohammed Ahmad Aserri1 ${ }^{*}$, Fatma Mostafa Baddar ${ }^{2,3}$, Salha Mohammed Ahmad Aserri ${ }^{4}$ \\ ${ }^{1}$ Nursing Education \& Administration, Head of Academic Affair in ABHA Health Sector, Ministry of Health, Aseer Region, Abha, \\ KSA \\ ${ }^{2}$ Nursing Administration and Education Department, College of Nursing, King Saud University, Al Riyadh, KSA \\ ${ }^{3}$ Nursing Administration Department, Faculty of Nursing, Alexandria University, Alexandria, Egypt \\ ${ }^{4}$ Nursing Education \& Administration, Head of Academic Affair in General Directorate of Health Affairs ABHA, Ministry of \\ Health, Aseer Region, Abha, KSA \\ Email: ^drmmafa2019@gmail.com
}

How to cite this paper: Aserri, M.M.A., Baddar, F.M. and Aserri, S.M.A. (2021) Prevalence of Occupational Stress and Related Risk Factors among Nurses Working in ASEER Region. Health, 13, 110-122. https://doi.org/10.4236/health.2021.132010

Received: January 8, 2021

Accepted: February 15, 2021

Published: February 18, 2021

Copyright (c) 2021 by author(s) and Scientific Research Publishing Inc. This work is licensed under the Creative Commons Attribution International License (CC BY 4.0).

http://creativecommons.org/licenses/by/4.0/

(cc) Open Access

\begin{abstract}
Background: Over the last century, stress as an interdisciplinary concept has become an area of great interest and has been researched extensively. Although the earliest studies on stress were mostly physiological, psychological models of stress have been developed and established a link between stressors and illness in his model of general adaptation syndrome. Objective: To investigate prevalence and factors associated with occupational stress among nurses working Asser region Hospital. The study included nurses at different age groups working at different departments with assessment of any sources of stress. Methodology: A descriptive cross-sectional study was conducted targeting nurses in the main hospitals in the Asser region, Southern Saudi Arabia. A total of the study samples of 217 nurses were required to estimate the expected average stress rate among nurses. A self-administered pre-structured questionnaire used for data collection. Results: Nurses' ages ranged 21 to 55 years old with mean age of $30.9 \pm 11.7$ years old. Majority of the nurses were females 175 (80.6\%). The highest mean score (more stress) was reported by nurses in relation to the following stress factors; working very hard $(4.3 \pm 0.9)$, followed by being under pressure to work long hours (4.2 \pm 0.9$)$, the opportunity given to do something is not real and enough (4.2 \pm 1.0 ). The findings showed a significant relationship between nurses' stress level, their personal and work-related characteristics $(P=0.001)$. Recommendations: Interventional programs to detect and alleviate sources and effects of occupational stress should be developed including more training re-
\end{abstract}


garding coping strategies, nurses' support, and better work condition.

\section{Keywords}

Stress, Nurses, Workload, Determinants, Factors Associated, Psychological Effect, Work Environment

\section{Background}

Recently, stress as an interdisciplinary concept has become an area of great interest and has been widely explored [1]. Work-related stress is the main issue under the focus of professions. Though, Work-Related Stress depends mainly on the nature of profession. Previous literature has demonstrated that the prevalence of stress is highly presented in Health Professions [2] [3]. This high level of stress is related to the type of tasks and responsibilities required in this kind of professions. In the last few years, much research focused on the relation between causes of work stress and the impact of work stress on health [4] [5] [6].

Nurses as one of the main diagonals in health practice, reported the highest level of stress [7] [8]. Consequently, Work-Related Stress in nurses is considered a common problem worldwide [9] [10]. Workplace stress has long been recognized as a challenge for the nursing profession. Nursing is a profession of high stress which affects physical as well as mental health of the nurses [11] [12].

Nursing job is an area of a constant stress. The practice of nursing profession mostly occurs in hospital environment. It is requiring highly trained nurses with behavioural and professional skills during care for patients. Patients who are away of their families and do not know about their future regarding their complaints make them start relying more on nurses for care, comfort, and proper attention for recovery, which in turn increases the nurse's burden and stress. A nurse provides necessary information regarding their disease and problem. Nurse remains with patients all day and night to help [13] [14] [15].

Generally, work related stress affects employees negatively in their accomplishment and performance at work, which could usually end up in often result in disappointments and be not satisfied with their successes [16]. It is important to motivate nurses for them to achieve their everyday jobs, supply worth care and contribute to the growth of nursing profession [17]. The current study aimed to assess prevalence and factors associated with occupational stress among nurses working in main hospitals in ASEER region, Southern of Saudi Arabia.

\section{Methodology}

A descriptive cross-sectional study was conducted targeting nurses in Asser region, Southern Saudi Arabia, at hospitals (one military and five civil hospitals) covering the whole region with the whole workable nurses in region. Inclusion 
criteria for nurse enrolment were staff nurse working in technical position, have completed at least six months of service (to ensure that participants have at least some familiarity with the job and organization), and be willing to participate in the study. A total sample of 217 nurses of total 500 available nurses were required to estimate expected average stress rate among nurses in Asser region hospitals of 53\% [9] [10] [11] using precision of 5\% at 95\% confidence level. Sample size was calculated using STATA 11 software using previously listed parameters. Nurses were included from the different hospitals randomly based probability proportionate to size (PPS) after explaining study objectives and confirming data confidentiality. Within each hospital, nurses were included from different departments by simple random sample using checklist from hospital administration. Non existing nurse at interview day was replaced by the next one till the required sample size fulfilled. A self-administered pre-structured questionnaire used for data collection. Questionnaire was initiated by researchers after intensive literature review and expert's consultation. It consists of two sections; first section covered demographic data, job related data and nurse work environment. Second section will include HSE standard job stress survey. It consisted of 34 items on five-point Linker scale (never, rarely, sometimes, often, and always). Scores of each item showed measured value of the item with change range of $1-5$, where 1 denotes undesirable state and 5 denotes desirable state. Highest score was 170 and lowest score was 34 . Score lower than 80 denoted poor stress, score between 80 - 125 denoted average score and scores above 125 were considered as high score. Cranach's alpha coefficient of the questionnaire was obtained as 0.78 in the study by Akbari $\mathrm{H}$ et al. [18] [19] Pilot study was conducted on 20 nurses who were excluded from the final study. Pilot study showed tool reliability (Cranach's alpha) of 0.83 .

\section{Data Collection Procedures}

All authors acknowledge all nurses who paid their time completing the study questionnaire helping us to finalize the work. Period of data collection Begun from 02\07\2020 till 6 months ago, a total sample of 217 nurses of total 500 nurses is drawn to estimate expected stress rate among nurses in Asser region hospitals of $53 \%$ using precision of $5 \%$ at $95 \%$ confidence level. Sample size was calculated using STATA 11 software using previously listed parameters.

\section{Ethical Considerations}

The study was approved by health affairs-ASEER region research ethical committee with approval No. REC-NO (REC-12-06-2020). participants' consent to participate; have sufficient information regarding the research and have the power to withdraw from the study at any stage. In this study, a written cover letter verifying the purpose of the study and the type of data that collected and ensure anonymity and confidentiality of subject was attached to each questionnaire sheet. Followed by an informed consent that confirms the participants' under- 
standing of the information in cover letter and accepting the participation was considered as the consent. Participants informed that participation is voluntary, and they have the right not to answer any question(s) and/or withdraw from the study at any stage without any penalty. There are no apparent risks or benefits for the participants in this study. The researchers have maintained the anonymity of participants in the study by removing any names and identifiable.

\section{Data Analysis}

After data were extracted, it was revised, coded, and fed to statistical software IBM SPSS version 22 (SPSS, Inc. Chicago, IL). All statistical analysis was done using two tailed tests. P value less than 0.05 was statistically significant. Stress level was assessed by summing-up all discrete scores for the HSE standard job stress survey, then patients stress scores were categorized reference to methodology section. Descriptive analysis based on frequency and percent distribution was done for all variables including nurse's demographic data, work data, and stress scale discrete items. Crosstabulation was used to assess distribution of nurses' level of stress according to their bio-demographic and work data. Relations significance was tested using Pearson chi-square test.

\section{Results}

The study included 217 nurses who completed the study questionnaire. Nurses ages ranged 21 to 55 years old with mean age of $(30.9 \pm 11.7)$ years old. Majority of the nurses were females 175 (80.6\%). As for qualification, 139 (64.1\%) nurses had bachelor's degree and only 13 (6\%) had master's degree. Exact of 134 (61.8\%) nurses were married and 28 (12.9\%) had chronic health problems. Also, $42(19.4 \%)$ nurses had family member or child who needs special care (Table 1 ).

As for work data (Table 2), exact of 97 (44.7\%) had experience of 10 years or more in nursing profession, and 89 (41\%) had hospital experience of 10 years or more. Exact of 50 (23\%) nurses worked at ICU, 47 (21.7\%) at medicine word, 41 (18.9\%) at OPD, and $35(16.1 \%)$ nurses at surgery department. Morning shift work was reported among 98 (45.2\%) nurses and 115 (53\%) had mixed shifts. Exact of $132(60.8 \%)$ nurses care for less than 10 patients daily. Working for more than 8 hours daily was reported by 103 (47.5\%) nurses and 199 (91.7\%) work for 5 days weekly.

Table 3 illustrates distribution of stress items among nurses in ASEER region hospitals. The highest mean score (more stress) was reported by nurses in relation to the following stress factors; working very hard ( $4.3 \pm 0.9)$, followed by being under pressure to work long hours $(4.2 \pm 0.9)$, the opportunity given to do something is not real and enough (4.2 \pm 1.0$)$, no enough time to do tasks (4.0 \pm $1.1)$, no enough time for rest $(4.1 \pm 1.0)$, they should work at high speed. $(4.0 \pm$ 1.0). While the least stress factor stated by nurses was, have freedom of action in my work $(2.0 \pm 1.1)$. Totally, $78.8 \%$ of the nurses had moderate stress level and $13.8 \%$ had high stress level (Figure 1). 
Table 1. Personal characteristics of sampled nurses in ASEER region hospitals.

\begin{tabular}{|c|c|c|c|}
\hline \multicolumn{2}{|c|}{ Personal characteristics } & No & $\%$ \\
\hline \multirow{4}{*}{ Age in years } & $21-30$ & 90 & $41.5 \%$ \\
\hline & $31-40$ & 90 & $41.5 \%$ \\
\hline & $41-45$ & 26 & $12.0 \%$ \\
\hline & $46-55$ & 11 & $5.1 \%$ \\
\hline \multirow{2}{*}{ Gender } & Male & 42 & $19.4 \%$ \\
\hline & Female & 175 & $80.6 \%$ \\
\hline \multirow{3}{*}{ Qualification } & Bachelor & 139 & $64.1 \%$ \\
\hline & Diploma & 65 & $30.0 \%$ \\
\hline & Master & 13 & $6.0 \%$ \\
\hline \multirow{3}{*}{ Marital status } & Single & 56 & $25.8 \%$ \\
\hline & Married & 134 & $61.8 \%$ \\
\hline & Divorced/widow & 27 & $12.4 \%$ \\
\hline \multirow{2}{*}{ Nationality } & Saudi & 190 & $87.6 \%$ \\
\hline & Non-Saudi & 27 & $12.4 \%$ \\
\hline \multirow{2}{*}{ Chronic health problem } & Yes & 28 & $12.9 \%$ \\
\hline & No & 189 & $87.1 \%$ \\
\hline \multirow{2}{*}{ Family members need special care } & Yes & 42 & $19.4 \%$ \\
\hline & No & 175 & $80.6 \%$ \\
\hline
\end{tabular}

Table 2. Work related data of nurses in ASEER region hospitals.

\begin{tabular}{|c|c|c|c|}
\hline \multicolumn{2}{|c|}{ Work related data } & \multirow{2}{*}{$\begin{array}{c}\text { No } \\
59\end{array}$} & \multirow{2}{*}{$\begin{array}{c}\% \\
27.2 \%\end{array}$} \\
\hline & $<5$ years & & \\
\hline \multirow[t]{3}{*}{ Job Experience years } & $5-10$ years & 61 & $28.1 \%$ \\
\hline & $>10$ years & 97 & $44.7 \%$ \\
\hline & $<5$ years & 71 & $32.7 \%$ \\
\hline \multirow[t]{5}{*}{ Hospital experience years } & $5-10$ years & 57 & $26.3 \%$ \\
\hline & $>10$ years & 89 & $41.0 \%$ \\
\hline & Disaster & 2 & $0.9 \%$ \\
\hline & ER & 34 & $15.7 \%$ \\
\hline & ICU & 50 & $23.0 \%$ \\
\hline \multirow{5}{*}{ Department } & Medicine ward & 47 & $21.7 \%$ \\
\hline & Oncology & 4 & $1.8 \%$ \\
\hline & OPD & 41 & $18.9 \%$ \\
\hline & Others & 4 & $1.8 \%$ \\
\hline & Surgery & 35 & $16.1 \%$ \\
\hline Shift & Morning & 98 & $45.2 \%$ \\
\hline
\end{tabular}




\section{Continued}

\begin{tabular}{cccc}
\hline Evening & 2 & $0.9 \%$ \\
& Night & 2 & $0.9 \%$ \\
& Mixed & 115 & $53.0 \%$ \\
\hline Number of patients cared per day & $<10$ & 132 & $60.8 \%$ \\
& $10-29$ & 50 & $23.0 \%$ \\
Daily work hours & $30+$ & 35 & $16.1 \%$ \\
& $<8$ hours & 114 & $52.5 \%$ \\
& $>8$ hours & 103 & $47.5 \%$ \\
\hline Workdays per week & $<5$ days & 18 & $8.3 \%$ \\
& 5 days & 199 & $91.7 \%$ \\
\hline
\end{tabular}

Table 3. Distribution of stress items among nurses in ASEER region hospitals.

\begin{tabular}{|c|c|c|c|}
\hline Stress items & Mean & SD & Rank \\
\hline Clearly know what is expected of me at work. & 3.5 & 1.1 & 13 \\
\hline I can decide when to rest. & 2.2 & 1.2 & 25 \\
\hline Different groups at work want me to do things that are hard to combine them. & 3.8 & 1.1 & 9 \\
\hline I know a way to do things to in my work. & 3.4 & 1.2 & 15 \\
\hline I'm exposed to offense by bearing the ugly words and undesirable behaviour. & 3.5 & 1.4 & 11 \\
\hline I do not have enough time for tasks and duties. & 4.0 & 1.1 & 5 \\
\hline When I face a work problem, my colleagues help me. & 3.0 & 1.1 & 16 \\
\hline I get others' comment about my work. & 2.9 & 1.1 & 17 \\
\hline I must work very hard. & 4.3 & 0.9 & 1 \\
\hline I have freedom of action in my work. & 2.0 & 1.1 & 26 \\
\hline I am aware of my duties and responsibilities. & 3.6 & 1.1 & 12 \\
\hline Due to high load of work, I have to neglect some of the tasks. & 3.8 & 1.3 & 8 \\
\hline I'm aware of the goals and visions for my job. & 3.7 & 1.0 & 10 \\
\hline There are a tense relation among my colleagues. & 3.5 & 1.2 & 13 \\
\hline I have right of choice in doing my works. & 2.2 & 1.1 & 26 \\
\hline I do not have enough time to rest. & 4.1 & 1.0 & 4 \\
\hline I'm aware of what I'm doing is part of the organization's objectives. & 3.5 & 1.1 & 14 \\
\hline I am under pressure to work long hours. & 4.2 & 0.9 & 2 \\
\hline I have right of choice to do what in the environment. & 2.2 & 1.2 & 25 \\
\hline I have to work in high speed. & 4.0 & 1.0 & 6 \\
\hline I'm exposed to harassment in the workplace. & 2.6 & 1.3 & 19 \\
\hline The opportunity given to do something is not real and enough. & 4.2 & 1.0 & 3 \\
\hline In dealing with problems, I can count on the help of my manager. & 2.8 & 1.1 & 19 \\
\hline If I need my colleagues help me. & 2.9 & 1.1 & 18 \\
\hline
\end{tabular}




\section{Continued}

\begin{tabular}{lccc}
\hline I have opinions on what I'm doing. & 2.2 & 1.2 & 25 \\
I have enough time to ask the manager about the changes. & 2.5 & 1.1 & 21 \\
I enjoy necessary and sufficient respect by my colleagues at workplace. & 3.1 & 1.1 & 15 \\
In my work environment, changes are always consulted with staff. & 2.4 & 1.3 & 22 \\
I can talk with my boss about something that has bothered me. & 2.8 & 1.0 & 20 \\
The operating hours may be changed. & 3.9 & 1.1 & 7 \\
My colleagues are prepared to pay attention to my working problems. & 2.7 & 1.0 & 20 \\
When changes occur in things, I am clearly aware of their practicality. & 2.4 & 1.1 & 23 \\
When doing things that emotionally heavy, I am helped. & 3.1 & 1.1 & 16 \\
My relationships at work are strained. & 2.3 & 1.3 & 24 \\
Overall stress score. & 3.1 & 0.112 &
\end{tabular}

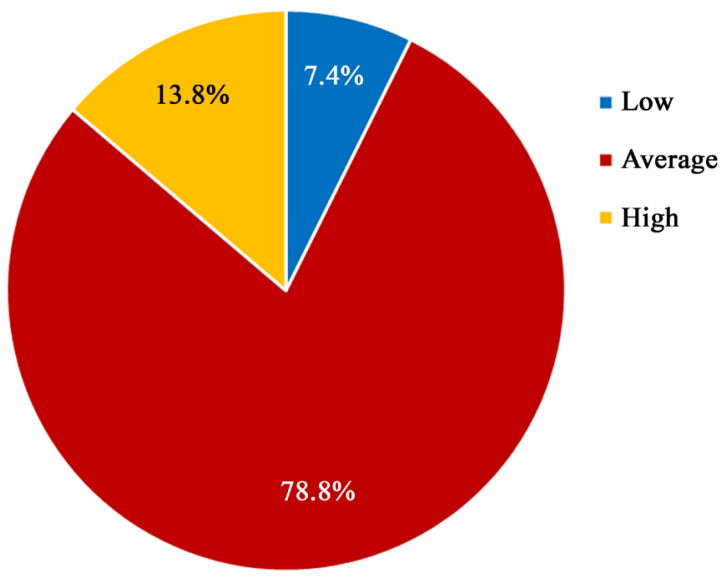

Figure 1. Overall stress level among nurses in ASEER region hospitals.

Table 4 shows distribution of nurses' stress level by their personal data among nurses in ASEER region hospitals. High stress was detected among $36.4 \%$ of old aged nurses compared to $7.8 \%$ of nurses below the age of 30 years with recorded statical significance $(\mathrm{P}=0.032)$. Exact of $24.6 \%$ of nurses with diploma degrees complained of high stress compared to $7.7 \%$ of those who had master's degree ( $\mathrm{P}$ $=0.025)$. Also, high stress level was detected among $28.6 \%$ of nurse with chronic health problem compared to $11.6 \%$ of those who did not $(\mathrm{P}=0.046)$. Exact of $38.1 \%$ of nurses who had family member need special care had high stress compared to $8 \%$ of others $(\mathrm{P}=0.001)$.

Table 5 demonstrates distribution of nurses' stress level by their work data among nurses in ASEER region hospitals. Exact of 17.5\% of nurses with experience exceeding 10 years had high stress level compared to $10.2 \%$ of those who had experience less than 5 years $(P=0.013)$. The highest level of stress was experienced by nurses at OPD (36.6\%) compared to none at wards $(\mathrm{P}=0.001)$. About $18.5 \%$ of nurses work at morning shifts had high stress compared to none of those who work at evening and night shifts $(\mathrm{P}=0.024)$. Also, $57.1 \%$ of nurses 
Table 4. Distribution of nurses' stress level by their personal data among nurses in ASEER region hospitals.

\begin{tabular}{|c|c|c|c|c|c|c|c|c|}
\hline \multirow{2}{*}{\multicolumn{2}{|c|}{ Personal data }} & \multicolumn{6}{|c|}{ Stress level } & \multirow{3}{*}{$P$-value } \\
\hline & & \multicolumn{2}{|c|}{ Low } & \multicolumn{2}{|c|}{ Average } & \multicolumn{2}{|c|}{ High } & \\
\hline & & No & $\%$ & No & $\%$ & No & $\%$ & \\
\hline \multirow{4}{*}{ Age in years } & $21-30$ & 11 & $12.2 \%$ & 72 & $80.0 \%$ & 7 & $7.8 \%$ & \multirow{4}{*}{$0.032^{*}$} \\
\hline & $31-40$ & 4 & $4.4 \%$ & 71 & $78.9 \%$ & 15 & $16.7 \%$ & \\
\hline & $41-45$ & 0 & $0.0 \%$ & 22 & $84.6 \%$ & 4 & $15.4 \%$ & \\
\hline & $46-55$ & 1 & $9.1 \%$ & 6 & $54.5 \%$ & 4 & $36.4 \%$ & \\
\hline \multirow{2}{*}{ Gender } & Male & 5 & $11.9 \%$ & 32 & $76.2 \%$ & 5 & $11.9 \%$ & \multirow{2}{*}{0.442} \\
\hline & Female & 11 & $6.3 \%$ & 139 & $79.4 \%$ & 25 & $14.3 \%$ & \\
\hline \multirow{3}{*}{ Qualification } & Bachelor & 13 & $9.4 \%$ & 113 & $81.3 \%$ & 13 & $9.4 \%$ & \multirow{3}{*}{$0.025^{\star}$} \\
\hline & Diploma & 3 & $4.6 \%$ & 46 & $70.8 \%$ & 16 & $24.6 \%$ & \\
\hline & Master & 0 & $0.0 \%$ & 12 & $92.3 \%$ & 1 & $7.7 \%$ & \\
\hline \multirow{3}{*}{ Marital status } & Single & 7 & $12.5 \%$ & 41 & $73.2 \%$ & 8 & $14.3 \%$ & \multirow{3}{*}{0.495} \\
\hline & Married & 8 & $6.0 \%$ & 107 & $79.9 \%$ & 19 & $14.2 \%$ & \\
\hline & $\begin{array}{l}\text { Divorced/ } \\
\text { widow }\end{array}$ & 1 & $3.7 \%$ & 23 & $85.2 \%$ & 3 & $11.1 \%$ & \\
\hline \multirow{2}{*}{ Nationality } & Saudi & 15 & $7.9 \%$ & 149 & $78.4 \%$ & 26 & $13.7 \%$ & \multirow{2}{*}{0.736} \\
\hline & Non-Saudi & 1 & $3.7 \%$ & 22 & $81.5 \%$ & 4 & $14.8 \%$ & \\
\hline \multirow{2}{*}{$\begin{array}{l}\text { Chronic health } \\
\text { problem }\end{array}$} & Yes & 1 & $3.6 \%$ & 19 & $67.9 \%$ & 8 & $28.6 \%$ & \multirow{2}{*}{$0.046^{*}$} \\
\hline & No & 15 & $7.9 \%$ & 152 & $80.4 \%$ & 22 & $11.6 \%$ & \\
\hline \multirow{2}{*}{$\begin{array}{l}\text { Family members } \\
\text { need special care }\end{array}$} & Yes & 1 & $2.4 \%$ & 25 & $59.5 \%$ & 16 & $38.1 \%$ & \multirow{2}{*}{$0.001^{*}$} \\
\hline & No & 15 & $8.6 \%$ & 146 & $83.4 \%$ & 14 & $8.0 \%$ & \\
\hline
\end{tabular}

P: Pearson $X^{2}$ test; ${ }^{*} \mathrm{P}<0.05$ (significant).

Table 5. Distribution of nurses' stress level by their work data among nurses in ASEER region hospitals.

\begin{tabular}{|c|c|c|c|c|c|c|c|c|}
\hline & & \multicolumn{6}{|c|}{ Stress level } & \multirow{3}{*}{ P-value } \\
\hline \multicolumn{2}{|c|}{ Work related data } & \multicolumn{2}{|c|}{ Low } & \multicolumn{2}{|c|}{ Average } & \multicolumn{2}{|c|}{ High } & \\
\hline & & No & $\%$ & No & $\%$ & No & $\%$ & \\
\hline \multirow{3}{*}{ Experience years } & $<5$ years & 9 & $15.3 \%$ & 44 & $74.6 \%$ & 6 & $10.2 \%$ & \multirow{3}{*}{$0.013^{*}$} \\
\hline & 5 - 10 years & 6 & $9.8 \%$ & 48 & $78.7 \%$ & 7 & $11.5 \%$ & \\
\hline & $>10$ years & 1 & $1.0 \%$ & 79 & $81.4 \%$ & 17 & $17.5 \%$ & \\
\hline \multirow{3}{*}{$\begin{array}{c}\text { Hospital } \\
\text { experience years }\end{array}$} & $<5$ years & 9 & $12.7 \%$ & 55 & $77.5 \%$ & 7 & $9.9 \%$ & \multirow{3}{*}{0.152} \\
\hline & 5 - 10 years & 4 & $7.0 \%$ & 46 & $80.7 \%$ & 7 & $12.3 \%$ & \\
\hline & $>10$ years & 3 & $3.4 \%$ & 70 & $78.7 \%$ & 16 & $18.0 \%$ & \\
\hline \multirow{2}{*}{ Department } & Disaster & 0 & $0.0 \%$ & 2 & $100.0 \%$ & 0 & $0.0 \%$ & \multirow[b]{2}{*}{$0.001^{\star}$} \\
\hline & ER & 1 & $2.9 \%$ & 21 & $61.8 \%$ & 12 & $35.3 \%$ & \\
\hline
\end{tabular}




\begin{tabular}{|c|c|c|c|c|c|c|c|c|}
\hline & ICU & 10 & $20.0 \%$ & 37 & $74.0 \%$ & 3 & $6.0 \%$ & \\
\hline & Medicine ward & 3 & $6.4 \%$ & 44 & $93.6 \%$ & 0 & $0.0 \%$ & \\
\hline & Oncology & 0 & $0.0 \%$ & 4 & $100.0 \%$ & 0 & $0.0 \%$ & \\
\hline & OPD & 1 & $2.4 \%$ & 25 & $61.0 \%$ & 15 & $36.6 \%$ & \\
\hline & Others & 0 & $0.0 \%$ & 4 & $100.0 \%$ & 0 & $0.0 \%$ & \\
\hline & Surgery & 1 & $2.9 \%$ & 34 & $97.1 \%$ & 0 & $0.0 \%$ & \\
\hline \multirow{4}{*}{ Shift } & Morning & 2 & $2.0 \%$ & 78 & $79.6 \%$ & 18 & $18.4 \%$ & \multirow{4}{*}{$0.024^{*}$} \\
\hline & Evening & 0 & $0.0 \%$ & 2 & $100.0 \%$ & 0 & $0.0 \%$ & \\
\hline & Night & 1 & $50.0 \%$ & 1 & $50.0 \%$ & 0 & $0.0 \%$ & \\
\hline & Mixed & 13 & $11.3 \%$ & 90 & $78.3 \%$ & 12 & $10.4 \%$ & \\
\hline \multirow{3}{*}{$\begin{array}{c}\text { Number of patients } \\
\text { cared per day }\end{array}$} & $<10$ & 15 & $11.4 \%$ & 114 & $86.4 \%$ & 3 & $2.3 \%$ & \multirow{3}{*}{$0.001^{\star}$} \\
\hline & $10-29$ & 0 & $0.0 \%$ & 43 & $86.0 \%$ & 7 & $14.0 \%$ & \\
\hline & $30+$ & 1 & $2.9 \%$ & 14 & $40.0 \%$ & 20 & $57.1 \%$ & \\
\hline \multirow{2}{*}{ Daily work hours } & $<8$ hours & 8 & $7.0 \%$ & 93 & $81.6 \%$ & 13 & $11.4 \%$ & \multirow{2}{*}{0.523} \\
\hline & $>8$ hours & 8 & $7.8 \%$ & 78 & $75.7 \%$ & 17 & $16.5 \%$ & \\
\hline \multirow{2}{*}{$\begin{array}{l}\text { Workdays per } \\
\text { week }\end{array}$} & $<5$ days & 1 & $5.6 \%$ & 16 & $88.9 \%$ & 1 & $5.6 \%$ & \multirow{2}{*}{0.519} \\
\hline & 5 days & 15 & $7.5 \%$ & 155 & $77.9 \%$ & 29 & $14.6 \%$ & \\
\hline
\end{tabular}

P: Pearson $\mathrm{X}^{2}$ test; ${ }^{*} \mathrm{P}<0.05$ (significant).

who care for 30 patients or more daily experienced high stress compared to $2.3 \%$ of those who care for less than 10 patients $(\mathrm{P}=0.001)$.

\section{Discussion}

Nurses play a significant role in the provision of health care. Nurses are the intermediate link between the physician and the patient in health care delivery [20]. Long shifts for many days are the feature of nurses' work, especially in hospitals, and this is physically exhausting. Besides, nurses work environment is filled with those suffering daily. Nursing requires a high level of care to guarantee patient safety in their complicated work environment. Medical emergencies, and nurses deal with misery and loss when a patient dies, all of these factors can increase a nurse's stress level and affect nurse health [21] [22] [23] [24].

Regarding stress, the majority of nurses (79\%) were in the yellow zone (intermediate stress level) but also about $14 \%$ of the nurses experienced high stress level with mean stress score of 107 out of 170 . The most reported stress areas were nurses' perception of working very, being under pressure to work long hours, the opportunity given to do something is not real and enough, no enough time for rest, no enough time to do tasks, and they should work at high speed. All these factors are formed of two main items, high workload and lack of time which made nurses under pressure. This can be more explained if we noticed that nearly half of the study nurses work for more than 8 hours daily for 5 days 
per week. But on the other side, nearly two thirds of the study nurses care for less than 10 patients daily and this explains that most of them are moderately but not highly stressed. This estimated stress was consistent with what reported by Dagget $\mathrm{T}$ et al., [24] who assessed mean score of job-related stress among nurses working in Jimma Zone public hospitals by 58.5 out of 116 . Sharma P et al., [25] reported that $42 \%$ were suffering from moderate-to-severe stress. Nurses reported that they had no time for rest, with poor physician attitude. In Ghana, Godwin A et al., [26] conducted a study on nurses' stress and coping strategies. The study revealed that inadequate motivation, inadequate staffing levels, handling a large number of patients alone, lack of break during shift and nursing difficult patients were the most sources of stress. Other studies assessed similar level of stress among nurses at different work conditions [27] [28] [29] [30]. On the other hand, Sreelekha B. et al., [31] assessed higher level of stress among nurses than what the current study. The study revealed that $1 \%$ of the nurses had mild stress, $39.5 \%$ had moderate stress and 59.5\% had severe stress. There are other many studies which indicted higher level of occupational stress among hospital nurses [32] [33] [34]. These variations may be attributed to the difference in perceptions of the nurses and their cultures regarding what is the medical care taxes and how to cope with. Also, it may be due to differences of methods used to assess stress as some studies used quantitative tools and other used qualitative assessment and perceived stress among nurses.

Regarding factors associated with stress, the current study revealed that higher stress was associated with nurses old age with diploma qualification. Those nurses are not the seniors in the job hierarchy as younger nurses are more qualified (master's degree) making old, aged nurses under stress due to more job tasks they should perform. Also, the higher stress level was detected among nurses with chronic health problem and those who had family member need special care. This made nurses have more affairs out of their work environment ending by being stressed due to the high familiar and work burden. Nurses who worked in the morning shifts were more stressed and this mostly due to the higher workload (main time for patients' attendance and care). This can be evidenced by that more than half of nurses who care for 30 patients or more daily were highly stressed. These findings regarding source of stress were consistent with what reported in the literature but other may covered more factors related to their hospital's administration, physician attitude, patients contact, death of patients and burnout [35].

\section{Study Limitation}

The main limitation was that the data collection using online tool which may target nurses who are interested and not faced by high burnout and those who have smart phones and internet accessibility. This may to some extent affect the precision of results and conclusions, but the current situation of COVID-19 pandemic gives us no other method. Researchers tried to cover most areas in the 
kingdom and to have the most available number of participants to release some limitations.

\section{Conclusion and Recommendations}

In conclusion, the study revealed that nurses in the main hospitals in ASEER region were moderately stressed. Higher stress level was reported among old, aged nurses with lower qualification. Also nurses who had chronic health problems or family member need special care were more stressed besides other factors related to high workload. The main stress related areas among the study nurses were time factor as most of them reported lack of time to do tasks, high workload, their need to hurry up to perform tasks, and no time for rest. More effort should be paid in health care settings, especially main hospitals, to investigate stress related factors, and its management in health care settings is recommended. Also, interventional programs to detect, and alleviate sources and effects of occupational stress should be developed including more training regarding coping strategies, nurses' support, and better work condition.

\section{Conflicts of Interest}

The authors declare no conflicts of interest regarding the publication of this paper.

\section{References}

[1] Jennings, B.M. (2008) Work Stress and Burnout among Nurses: Role of the Work Environment and Working Conditions. In: Hughes, R.G., Ed., Patient Safety and Quality: An Evidence-Based Handbook for Nurses, Agency for Healthcare Research and Quality (US), Rockville, MD.

[2] Lu, H., Barriball, K.L., Zhang, X. and While, A.E. (2012) Job Satisfaction among Hospital Nurses Revisited: A Systematic Review. International Journal of Nursing Studies, 49, 1017-1038. https://doi.org/10.1016/j.ijnurstu.2011.11.009

[3] Wilkins, K. (2007) Work Stress among Health Care Providers. Health Reports, 18, 33-36.

[4] Cole, M.S. and Bruch, H. (2006) Organizational Identity Strength, Identification, and Commitment and Their Relationships to Turnover Intention: Does Organizational Hierarchy Matter? Journal of Organizational Behavior, 27, 585-605. https://doi.org/10.1002/job.378

[5] Cummings, G., Hayduk, L. and Estabrooks, C. (2005) Mitigating the Impact of Hospital Restructuring on Nurses: The Responsibility of Emotionally Intelligent Leadership. Nursing Research, 54, 2-12. https://doi.org/10.1097/00006199-200501000-00002

[6] Aktharsha, U. and Anisa, H. (2011) Job Stress and Job Satisfaction: An Investigation of Nursing Personnel. The International Journal of Human Resource Management, 9, 18-32.

[7] Butterworth, T., Carson, J., Jeacock, J., White, E. and Clements, A. (1999) Stress, Coping, Burnout and Job Satisfaction in British Nurses: Findings from the Clinical Supervision Evaluation Project. Stress Medicine, 15, 27-33.

https://doi.org/10.1002/(SICI)1099-1700(199901)15:1<27::AID-SMI782>3.0.CO;2- 
$\underline{\mathrm{U}}$

[8] Alenezi, A.M., Aboshaiqah, A. and Baker, O. (2018) Work-Related Stress among Nursing Staff Working in Government Hospitals and Primary Health Care Centres. International Journal of Nursing Practice, 24, e12676. https://doi.org/10.1111/ijn.12676

[9] Chen, M.J. and Weng, S.S. (2017) Psychological Symptoms among Hospital Nurses in Taiwan: A Cross Sectional Study. BMC Women's Health, 17, Article No. 101. https://doi.org/10.1186/s12905-017-0460-5

[10] Gu, B., Tan, Q. and Zhao, S. (2019) The Association between Occupational Stress and Psychosomatic Wellbeing among Chinese Nurses: A Cross-Sectional Survey. Medicine, 98, e15836. https://doi.org/10.1097/MD.0000000000015836

[11] Vernekar, S.P. and Shah, H. (2018) A Study of Work-Related Stress among Nurses in a Tertiary Care Hospital in Goa. International Journal of Community Medicine and Public Health, 5, 657-661. https://doi.org/10.18203/2394-6040.ijcmph20180246

[12] Chen, J., Li, J., Cao, B., Wang, F., Luo, L. and Xu, J. (2020) Mediating Effects of Self-Efficacy, Coping, Burnout, and Social Support between Job Stress and Mental Health among Young Chinese Nurses. Journal of Advanced Nursing, 76, 163-173. https://doi.org/10.1111/jan.14208

[13] Kourakos, M. (2017) Mental Health and Coping Strategies among Nursing Staff in Public Health Services. Progress in Health Sciences, 7, 67-73. https://doi.org/10.5604/01.3001.0010.7852

[14] Peña, M., Ramos, M.M. and Topa, G. (2019) Occupational Stress in Nursing. Multiple Group Membership from a Preventive Perspective. Current Psychology, 1-9. https://doi.org/10.1007/s12144-019-00580-8

[15] Kakemam, E., Raeissi, P., Raoofi, S., Soltani, A., Sokhanvar, M., Visentin, D.C. and Cleary, M. (2019) Occupational Stress and Associated Risk Factors among Nurses: A Cross-Sectional Study. Contemporary Nurse, 55, 237-249. https://doi.org/10.1080/10376178.2019.1647791

[16] Gonnelli, C., Raffagnino, R. and Puddu, L. (2016) The Nurse Manager Training for an Efficient Leadership. 10th International Technology, Education and Development Conference, Valencia, Spain, 7-9 March 2016, 543-551. https://doi.org/10.21125/inted.2016.1137

[17] Manzoor, Z., Afzal, M., Azhar, M. and Gilani, S.A. (2018) Professional Stressors and Coping Strategies among Nurses. Journal of Health, Medicine and Nursing, 52, 43-47.

[18] Akbari, H., Satkin, M., Ganji, M., Akbari, H. and Gholami, F.M. (2017) Standardization and Study of Psychological Properties of the HSE Stress Questionnaire. Iranian Red Crescent Medical Journal, 19, e40466.

[19] Arbabisarjou, A., Ghoreishinia, G., Zare, S. and Shahrakipour, M. (2017) Study of Job Stress among Nurses Working in Teaching Hospitals. 9, 143-148.

[20] Choo, J., Hutchinson, A. and Bucknall, T. (2010) Nurses' Role in Medication Safety. Journal of Nursing Management, 18, 853-861.

https://doi.org/10.1111/j.1365-2834.2010.01164.x

[21] Beh, L.S. and Loo, L.H. (2012) Job Stress and Coping Mechanisms among Nursing Staff in Public Health Services. International Journal of Academic Research in Business and Social Sciences, 2, 131-176.

[22] Onasoga, O.A., Osamudiamen, O.S. and Ojo, A.A. (2013) Occupational Stress Management among Nurses in Selected Hospital in Benin City, Edo State, Nigeria. 
European Journal of Experimental Biology, 3, 473-481.

[23] Moustaka, E. and Constantinidis, T.C. (2010) Sources and Effects of Work-Related Stress in Nursing. Health Science Journal, 4, 210-216.

[24] Dagget, T., Molla, A. and Belachew, T. (2016) Job Related Stress among Nurses Working in Jimma Zone Public Hospitals, South West Ethiopia: A Cross Sectional Study. BMC Nursing, 15, Article No. 39. https://doi.org/10.1186/s12912-016-0158-2

[25] Sharma, P., Davey, A., Davey, S., Shukla, A., Shrivastava, K. and Bansal, R. (2014) Occupational Stress among Staff Nurses: Controlling the Risk to Health. Indian Journal of Occupational and Environmental Medicine, 18, 52-56. https://doi.org/10.4103/0019-5278.146890

[26] Godwin, A., Suuk, L.A. and Selorm, F.H. (2016) Occupational Stress and Its Management among Nurses at St. Dominic Hospital, Akwatia, Ghana. Health Science Journal, 10, 1-7. https://doi.org/10.21767/1791-809X.1000467

[27] Lambert, V.A., Lambert, C.E. and Ito, M. (2004) Workplace Stressors, Ways of Coping and Demographic Characteristics as Predictors of Physical and Mental Health of Japanese Hospital Nurses. International Journal of Nursing Studies, 41, 85-97. https://doi.org/10.1016/S0020-7489(03)00080-4

[28] Hughes, H. and Umeh, K. (2005) Work Stress Differentials between Psychiatric and General Nurses. British Journal of Nursing, 14, 802-808.

https://doi.org/10.12968/bjon.2005.14.15.18597

[29] Chang, E.M., Bidewell, J.W., Huntington, A.D., Daly, J., Johnson, A., Wilson, H., Lambert, V.A. and Lambert, C.E. (2007) A Survey of Role Stress, Coping and Health in Australian and New Zealand Hospital Nurses. International Journal of Nursing Studies, 44, 1354-1362. https://doi.org/10.1016/j.ijnurstu.2006.06.003

[30] Kshetrimayum, N., Bennadi, D. and Siluvai, S. (2019) Stress among Staff Nurses: A Hospital-Based Study. Journal of Nature and Science of Medicine, 2, 95-100.

[31] Sreelekha, B. and Rajeswari, H. (2016) Stress among Nurses in a Tertiary Care Hospital. The International Journal of Indian Psychology, 3, 155-164. https://doi.org/10.25215/0302.036

[32] Tyson, P.D. and Pongruengphant, R. (2004) Five-Year Follow-Up Study of Stress among Nurses in Public and Private Hospitals in Thailand. International Journal of Nursing Studies, 41, 247-254. https://doi.org/10.1016/S0020-7489(03)00134-2

[33] Lorenz, V.R., Benatti, M.C. and Sabino, M.O. (2010) Burnout and Stress among Nurses in a University Tertiary Hospital. Revista Latino-Americana de Enfermagem, 18, 1084-1091. https://doi.org/10.1590/S0104-11692010000600007

[34] Yau, S.Y., Xiao, X.Y., Lee, L.Y., Tsang, A.Y., Wong, S.L. and Wong, K.F. (2012) Job Stress among Nurses in China. Applied Nursing Research, 25, 60-64. https://doi.org/10.1016/j.apnr.2011.07.001

[35] Salilih, S.Z. and Abajobir, A.A. (2014) Work-Related Stress and Associated Factors among Nurses Working in Public Hospitals of Addis Ababa, Ethiopia: A Cross-Sectional Study. Workplace Health \& Safety, 62, 326-332. https://doi.org/10.1177/216507991406200803 